\title{
THE ACTION OF DIGITALIS IN HEART FAILURE WITH NORMAL RHYTHM
}

\author{
BY \\ PAUL WOOD \\ From the British Postgraduate Medical School and the National Hospital for Diseases of \\ the Heart \\ Received March 6, 1940
}

While it is generally accepted that digitalis may be of benefit in cases of congestive heart failure with normal rhythm, there is disagreement as to the frequency of such benefit, as to whether the ætiological type of heart disease influences the response, and as to the mechanism whereby the improvement is brought about. The present work deals in some measure with these three points.

It is not proposed to make an exhaustive survey of the earlier work, for this has been handled recently by Gavey and Parkinson (1939). They concluded that demonstrable benefit occurred in about half of the cases and that those with rheumatic heart disease responded better than all other ætiological types. They went further : they stated that cases of rheumatic heart disease responded better than other types, whether there was normal rhythm or auricular fibrillation, and since it is the rheumatic cases that characteristically fail with fibrillation they made the interesting suggestion that this might explain the timehonoured notion that heart failure with fibrillation responds better to digitalis than heart failure with normal rhythm. With regard to the third point : while in the common view digitalis improves the functional efficiency of the failing heart by direct action upon it, there are other opinions. Slowing of the heart rate with lengthening of the diastolic rest period is usually associated with the improvement and has been held responsible for it. There is also the view of Dock and Tainter (1930), supported by Katz and his co-workers (1938), that digitalis produces its beneficial effect upon failure with normal rhythm by its constrictor action upon the hepatic vessels, particularly the hepatic vein sphincter, operating " as a bloodless venesection." This conclusion is based on experiments with anæsthetized dogs without organic heart disease and has not been confirmed in man with congestive heart failure.

\section{MeTHODS OF INVESTIGATION}

In accordance with the back pressure theory, the essential effect of right ventricular failure is elevation of the systemic venous blood pressure. The 
degree of right ventricular failure was therefore estimated by direct measurement of the pressure in the antecubital vein, a procedure which is both simple and accurate. Other criteria were not used as a measure of the degree of congestive heart failure, and this needs no apology, for symptoms cannot as yet be measured accurately ; the size of the liver is difficult to assess clinically owing to alterations in the height of the diaphragm and to difficulty in determining its upper border ; œdema is capricious ; accurate measurement of diuresis requires control of too many factors ; and direct measurement of the cardiac output is complicated and often inaccurate, except in most experienced hands, and is not a measure of congestion. It may be said, however, that in no case was a fall in venous pressure accompanied by aggravation of symptoms, apparent enlargement of the liver, increase of œdema, or by apparent diminution of urinary output. The reverse was usually true and obvious diuresis occurred in some cases.

The venous blood pressure was determined in the following way. The patient was inclined at an angle of 45 degrees from the hips upwards, and the right shoulder and arm were bared and the arm placed comfortably on pillows well away from the trunk and approximately at the level of the fourth sternochondral junction. A wide-bore needle attached to a rubber tube was inserted into the right antecubital vein and strapped in position, the rubber tube being connected to an upright graduated glass tube fitted at its bottom with a T-piece, to which was connected a citrate reservoir, the whole system being filled with 3.8 per cent sodium citrate (see Fig. 1). The apparatus was supported by a

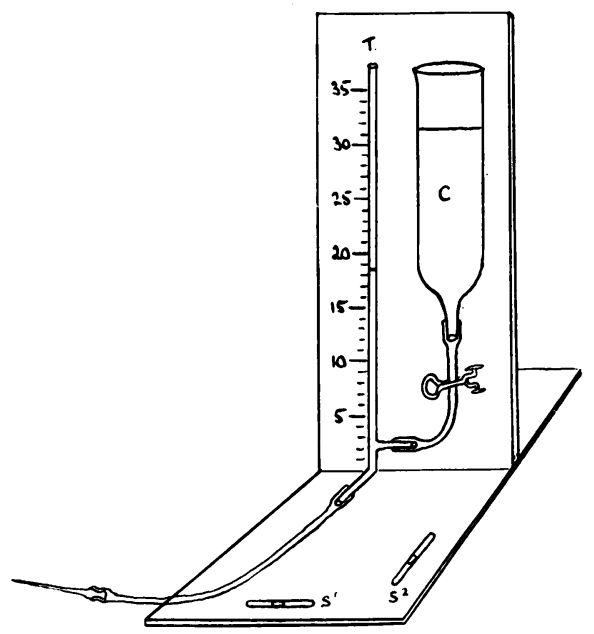

FIG. 1.-Apparatus for continuous measurement of the venous blood pressure.

T. Graduated glass tube.

C. Reservoir of $3 \cdot 8$ per cent sodium citrate.

$S^{i}$ and $S^{2}$ spirit levels.

wooden frame fitted with spirit levels so that the bottom of the graduated tube could be set at the level of the fourth right sterno-chondral junction by suitable manipulation of the base of the frame, and by releasing the cock momentarily 
every two or three minutes in order to flush the needle with citrate, continuous venous pressure measurements could be made indefinitely. (For normal controls see Wood, 1937.)

Although this work is primarily concerned with right ventricular failure, i.e. heart failure with systemic congestion, a few cases of isolated left ventricular failure were also studied, and in these the arm to tongue circulation time, as estimated by the decholin method (Wood, 1937), was used as the most simple and accurate measure of the degree of pulmonary congestion.

To ensure proper control, all cases of heart failure with normal rhythm admitted to hospital were put on absolute rest and received no treatment other than sedatives for a period not less than a week and averaging a fortnight ; patients who showed significant improvement were excluded from further study. The others then received digitalis in doses of 9 grains the first day, 6 grains the second day, and 3 grains of the powdered leaf thereafter, until therapeutic effects or symptoms of intoxication were observed.

By such means it was possible to determine the frequency of the benefit derived from digitalis, and whether certain ætiological types of heart disease responded better than others, but the method was too crude to provide any information as to the mechanism of digitalis action. For this purpose special observations were made. The subjects were kept at complete rest and the venous blood pressure recorded continuously ; after a period of at least half an hour, when a steady level had been reached, $1.5 \mathrm{mg}$. of digoxin was injected intravenously. The effects were then studied in relation to the pulse rate and to the size of the liver and spleen, and will be described in more detail later.

\section{RESULTS}

\section{Frequency of Benefit}

There were fifteen cases with right ventricular failure and normal rhythm, fourteen of which received demonstrable benefit from digitalis. Serial venous pressure measurements showed that the improvement was abrupt, and this is

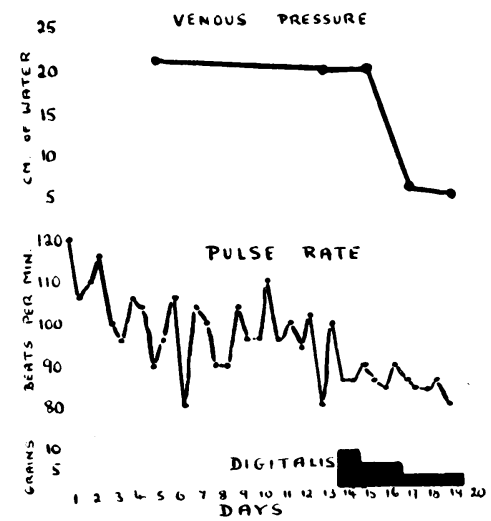

FIG. 2.-The action of digitalis on the venous blood pressure and pulse rate in a case of hypertension with right ventricular failure and normal rhythm. 
illustrated in Fig. 2, which is typical of the series. Table I shows the venous blood pressures and the average pulse rates before and after digitalis therapy in each of the fifteen cases, and it will be seen that with one exception the drop

TABLE I

The Venous Blood Pressure and Pulse Rate Before and After Digitalis in Right Ventricular Failure With Normal Rhythm

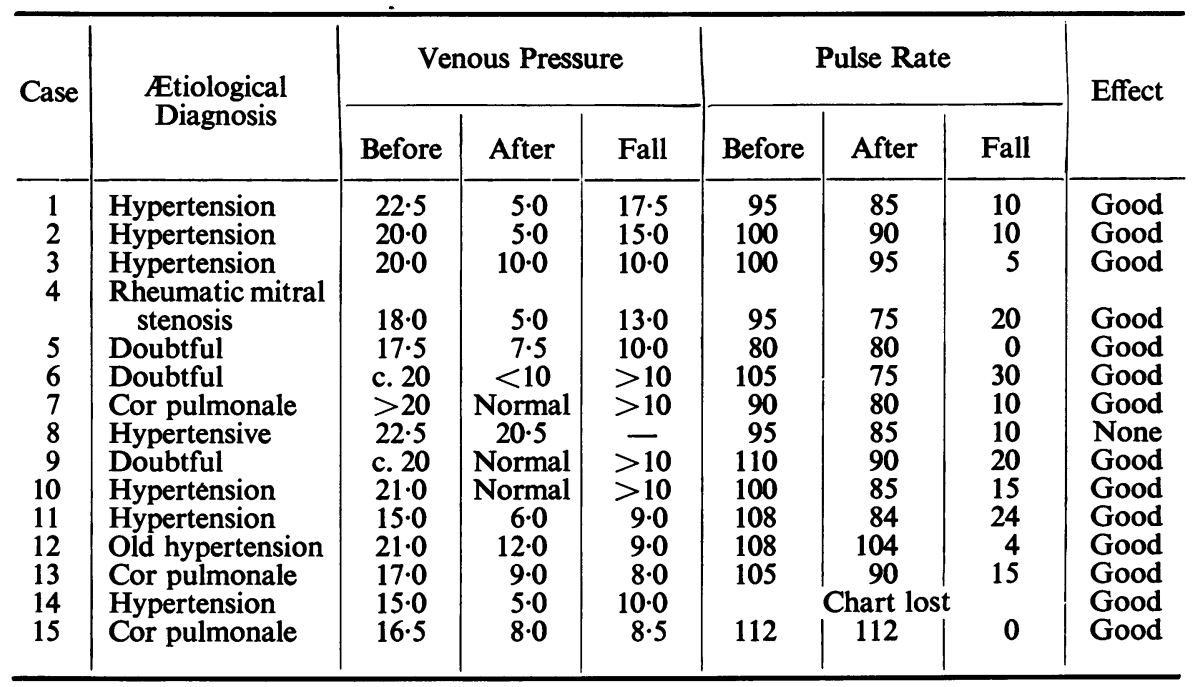

in the venous pressure was always considerable. Two of the three in which the æetiological diagnosis was not established came to autopsy later, and though the nature of the heart disease even then remained obscure, there was nothing to suggest that they were rheumatic. The third case likewise showed no clinical evidence of rheumatism. The patient who received no benefit died suddenly in rather a curious way. He had massive odema and weighed twenty stone, and after the failure of digitalis therapy, 2 c.c. of salyrgan injected intravenously resulted in an enormous diuresis, followed by slowing of the pulse rate from ninety to fifty beats per minute and sudden death. During the final two days his weight dropped $22 \mathrm{lb}$.

There were five cases with isolated left ventricular failure, congestion being confined to the pulmonary circuit. Serial observations on the arm to tongue circulation time showed significant improvement in four, but not in the fifth, which proved at autopsy to be one of periarteritis nodosa. Table II shows the arm to tongue circulation times and the average pulses rates before and after digitalis therapy in these five cases of left ventricular failure with normal rhythm. Fig. 3 illustrates the changes in the four cases with demonstrable improvement.

Thus, out of a series of twenty cases of congestive heart failure with normal rhythm, fifteen right and five left, eighteen responded to digitalis and two did not. Though the series is small it was well controlled and improvement was accurately measured and not a matter of opinion. 
TABLE II

The Circulation Time and Pulse Rate Before and. After Digitalis in Left Ventricular FaIluRe With Normal RHYThM

\begin{tabular}{|c|c|c|c|c|c|c|c|c|}
\hline \multirow{2}{*}{ Case } & \multirow{2}{*}{ Diagnosis } & \multicolumn{3}{|c|}{ Circulation Time (sec.) } & \multicolumn{3}{|c|}{ Pulse Rate } & \multirow{2}{*}{ Effect } \\
\hline & & Before & After & Fall & Before & After & Fall & \\
\hline 16 & $\begin{array}{l}\text { Hypertension } \\
\text { (Periarteritis) }\end{array}$ & 30 & 29 & - & 90 & 90 & 0 & None \\
\hline $\begin{array}{l}17 \\
18 \\
19 \\
20\end{array}$ & $\begin{array}{l}\text { Hypertension } \\
\text { Ischæmic } \\
\text { Hypertension } \\
\text { Hypertension }\end{array}$ & $\begin{array}{l}36 \\
25 \\
40 \\
27\end{array}$ & $\begin{array}{l}21 \\
18 \\
22 \\
22\end{array}$ & $\begin{array}{r}15 \\
7 \\
18 \\
5\end{array}$ & $\begin{array}{r}95 \\
90 \\
110 \\
75\end{array}$ & $\begin{array}{l}95 \\
80 \\
95 \\
60\end{array}$ & $\begin{array}{r}0 \\
10 \\
15 \\
15\end{array}$ & $\begin{array}{l}\text { Good } \\
\text { Good } \\
\text { Good } \\
\text { Fair }\end{array}$ \\
\hline
\end{tabular}

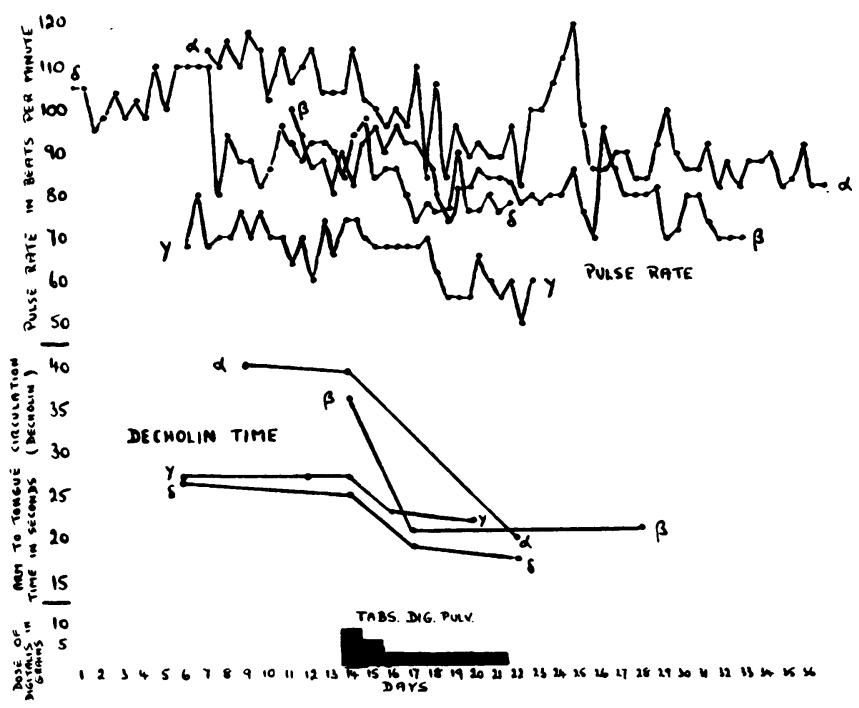

FIG. 3.-The action of digitalis on the arm-to-tongue circulation time and on the pulse rate in four cases of isolated left ventricular failure with normal rhythm.

The letters show which pulse chart corresponds to each circulation time chart. The length of the block representing digitalis therapy corresponds to case $y$, the drug being used for a longer period in the others.

\section{Influence of the Atiological Type of Heart Disease}

The ætiological diagnosis has been given in Tables I and II. There were twelve cases with hypertensive heart disease, three with chronic cor pulmonale, one with mitral stenosis, one with ischæmic heart disease, and in three the diagnosis of the condition was obscure (see p. 135). Thus, although eighteen out of twenty responded to digitalis, only one of these was rheumatic. It follows that if rheumatic heart disease responds better to digitalis than all ætiological types, it must respond very well indeed, for eighteen out of twenty is a proportion not often exceeded. 


\section{Mechanism of Digitalis Action}

1. Influence of the pulse rate.-In all but three of the long period studies the pulse rate fell with digitalis, on the average from 98 to 85 beats per minute. In two of the three with no fall in pulse rate digitalis effected an improvement. It has already been stated that two cases did not respond to digitalis. One of these showed a fall in pulse rate (from 95 to 85) and the other did not. Thus, with this crude method, it appears that although a fall in pulse rate is usually associated with improvement from digitalis therapy, it is not essential. (See Tables I and II.)

This point was investigated more thoroughly by means of four special observations. In the first (Fig. 4), $1 \mathrm{mg}$. of digoxin was injected intravenously

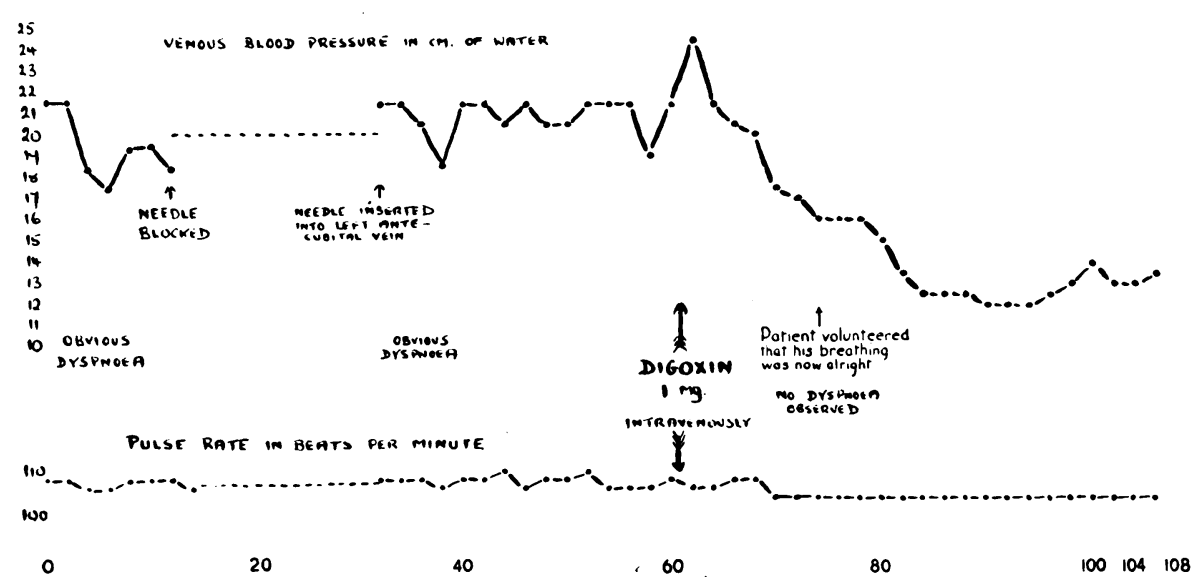

Fig. 4.-Continuous readings of the venous blood pressure and pulse rate in a case of right ventricular failure treated with intravenous digoxin.

when the venous blood pressure level had been steady at $21 \mathrm{~cm}$. of water for half an hour, and the pulse rate consistently between 105 and 110 beats per minute for an hour. The figure shows the rapid fall of the venous pressure to $12 \mathrm{~cm}$. of water, and the very slight drop in pulse rate to 104 beats per minute. This observation was repeated in another patient, and whereas the venous blood pressure fell from a steady level of 15 to $8 \mathrm{~cm}$. of water, the pulse rate remained constant at 112 beats per minute throughout. In the third observation a larger dose of digoxin $(1.5 \mathrm{mg}$.) was used, and as the venous blood pressure fell the pulse rate dropped sharply from 105 to 90 beats per minute (Fig. 5) ; atropine (1 mg.) was then injected intravenously and the pulse rate climbed back quickly to 105 , but the venous pressure continued to fall and finally reached normal limits. In the fourth observation chance proved an ally. After $1.5 \mathrm{mg}$. of digoxin the venous pressure fell from 15 to $7 \mathrm{~cm}$. of water, while the pulse rate rose steadily (Fig. 6). After a time the patient admitted that she had been suppressing a strong desire to micturate, but could hold her water no longer, and as it was not expedient for her to move, a catheter was passed and during its manipulation the venous pressure rose abruptly on account of her respiratory reactions. As the urine flowed the pulse rate 


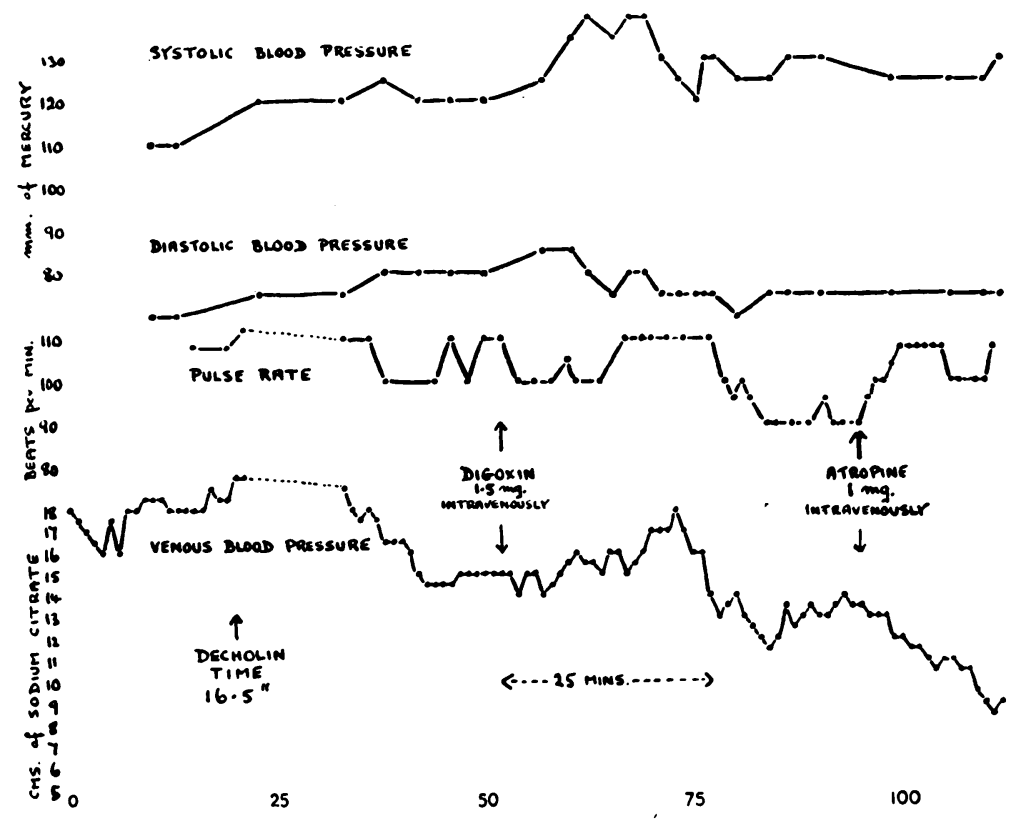

FIG. 5.-Continuous readings of the venous blood pressure and pulse rate in a case of right ventricular failure with normal rhythm treated with intravenous digoxin; the pulse rate fell as the venous pressure dropped, but after atropine it rose again to its previous level while the venous pressure continued to fall. (Note the slight rise of systolic blood pressure.)

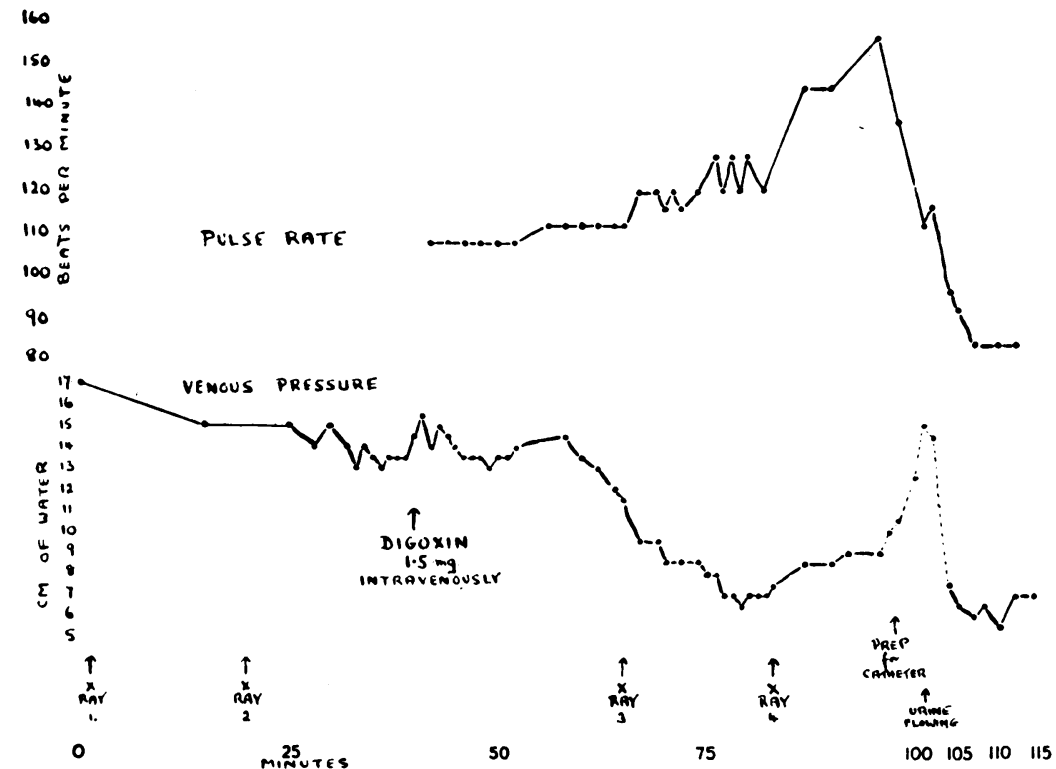

Fig. 6.- Showing how the pulse rate rose while the venous pressure fell after digoxin in a case of hypertension with right ventricular failure and normal rhythm; the curious behaviour of the pulse rate was due to a suppressed desire to micturate.

Serial X-ray films of the liver and spleen made radio-opaque by thorotrast were obtained in this case. The times at which these films were taken are marked. 
dropped sharply from 156 to 84 beats per minute and the venous pressure fell again to normal.

It is clear from these four observations that the drop in venous blood pressure effected by digitalis therapy in cases of congestive heart failure with normal rhythm is dissociated from coincident changes of pulse rate.

2. Influence of hepatic venous constriction.-If the theory of Dock and Tainter (1930), so ardently supported by Katz (1938), that digitalis acts like a "bloodless venesection," by constricting the hepatic veins and damming up the blood in the liver and spleen, be correct, then the liver and spleen should enlarge, as indeed these authors have demonstrated in animals. Clinically it is difficult to be sure of the upper borders of these viscera, but with the aid of thorotrast they may be visualized by means of X-rays. A patient with congestive heart failure and normal rhythm, with a bad prognosis, was injected with 75 c.c. of thorotrast intravenously in three divided doses at intervals of two days, until at the end of the week the liver and spleen were well seen on X-ray films. A special observation with $1.5 \mathrm{mg}$. of digoxin, similar to those already described, was then performed on a horizontal X-ray stand, so that control and serial X-ray films of the liver and spleen could be taken without disturbing the position of the patient. As the inferior border of the liver was exceptionally easy to feel, its position was frequently checked clinically by making serial marks on the abdominal wall. The venous blood pressure behaved as usual and fell from 14 to $7 \mathrm{~cm}$. of water (Fig. 6). Tracings from

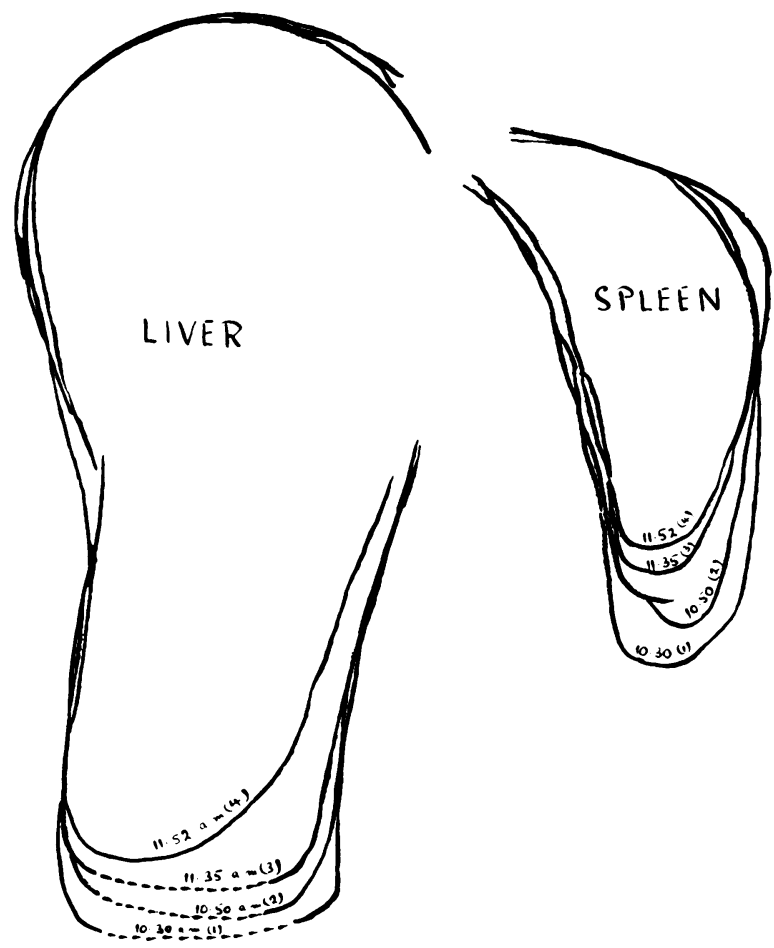

FIG. 7.-Superimposed tracings of the X-ray films of the liver and spleen from the case illustrated in Fig. 6 . The reduction in size of the liver was checked clinically. 
the serial X-ray films have been superimposed in Fig. 7, and it will be seen that coincident with the fall in venous pressure there was considerable reduction in size of both liver and spleen. This was supported by clinical evidence in respect of the lower margin of the liver, which was observed to move upwards more than an inch. It follows that the fall in venous pressure was not due to hepatic venous constriction or to portal venous constriction above the mouth of the splenic vein.

\section{CONCLUSIONS}

1. Digitalis effected demonstrable improvement in eighteen out of twenty cases of congestive heart failure with normal rhythm. This was judged by serial measurements of the venous blood pressure in those with systemic congestion, and of the arm-to-tongue circulation time in those with pulmonary congestion.

2. Since it has been stated that rheumatic heart disease responds better to digitalis than other ætiological types, it is of interest that only one of the present series was rheumatic.

3. Observations showed that the fall in venous blood pressure following intravenous digoxin was not due to slowing of the heart.

4. A single observation refuted the view that the beneficial action of digitalis is due to its constricting effect upon the hepatic vein.

My thanks are due to the Chief Medical Officer of the London County Council for his permission to publish these observations.

\section{REFERENCES}

Dock, W., and Tainter, M. L. (1930). J. Clin. Invest., 8, 467.

Gavey, C. J., and Parkinson, J. (1939). Brit. Heart J., 1, 27.

Katz, L. N., Mendlowitz, M., and Kaplan, H. A. (1938). Amer. Heart. J., 16, 149.

Katz, L. N., Rodbard, S., Friend, M., and Rottersman, W. (1938). J. Pharm. and Exper. Ther., 61, 1.

Stewart, H. J., Deitrick, J. E., Crane, N. F., and Wheeler, C. H. (1938). Arch. intern. Med., 62, 569.

Wood, P. (1936). Lancet, 2, 15. 